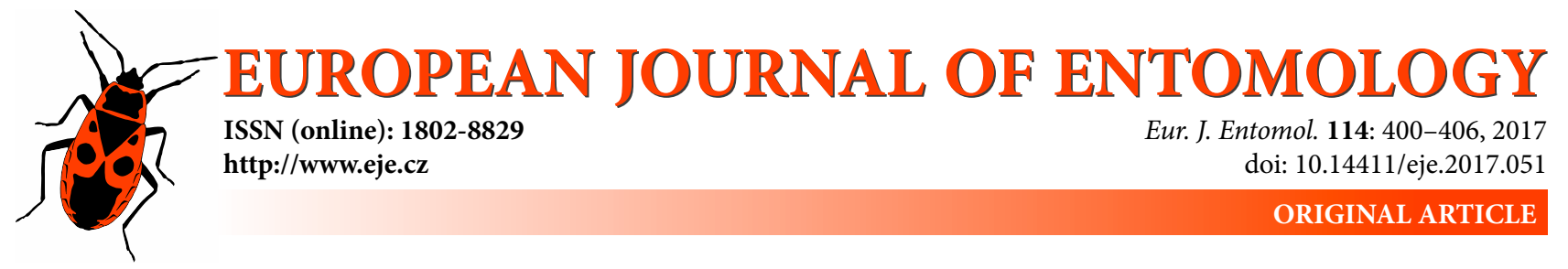

\title{
Effect of nutritious and toxic prey on food preference of a predaceous ladybird, Coccinella septempunctata (Coleoptera: Coccinellidae)
}

\author{
Mushtaq A. GUROO ${ }^{1}$, Ahmad PERVeZ ${ }^{2, *}$, Kuldeep SRIVAStAVA ${ }^{1}$ and Rakesh K. GUPTA ${ }^{1}$ \\ ${ }^{1}$ Division of Entomology, Sher-e-Kashmir University of Agricultural Sciences and Technology, Jammu - 180009, Chatha, Jammu \\ and Kashmir, India; gurookvk@gmail.com, kuldeep.ipm@gmail.com, rkguptaentoskuast@gmail.com \\ ${ }^{2}$ Biocontrol Laboratory, Department of Zoology, Radhey Hari Govt. P.G. College, Kashipur, US Nagar - 244713, Uttarakhand, \\ India; e-mail: ahmadpervez@yahoo.com
}

Key words. Coleoptera, Coccinellidae, Coccinella septempunctata, predatory potential, prey preference, Lipaphis erysimi, Brevicoryne brassicae

\begin{abstract}
We investigated the predatory potential and food preference of different life stages of Coccinella septempunctata L. for a nutritious aphid (mustard aphid, Lipaphis erysimi) and toxic aphid (cabbage aphid, Brevicoryne brassicae). We provided all the life stages of $C$. septempunctata with either L. erysimi or B. brassicae and found that the second, third and fourth instar larvae and adult females of this predator consumed daily greater numbers of $L$. erysimi. However, the first instar larvae and adult males consumed similar numbers of both of these aphids. In choice condition, each larva, adult males and females were each provided separately with a mixed aphid diet in three proportions (i.e. low: high, equal: equal and high: low densities of $L$. erysimi: $B$. brassicae). We hypothesized that life stages of $C$. septempunctata will prefer $L$. erysimi regardless of its proportions. Laboratory experiments supported this hypothesis only at the adult level in terms of high values of $\beta$ and $C$ preference indices. However, it rejects this hypothesis at the larval level, as larvae preferred $B$. brassicae when provided with certain combinations and showed no preference in a few combinations. We infer that mixtures of nutritious and toxic aphids may enable this ladybird to overcome any probable nutritional deficiency and/or reduce the toxicity of a toxic diet, especially for the larvae. Results of the treatment in which a high proportion of $B$. brassicae were consumed along with fewer $L$. erysimi indicates that a mixed diet could be better for the development of immature stages of $C$. septempunctata.
\end{abstract}

\section{INTRODUCTION}

Predatory potential and food preference are important aspects of a predator's biocontrol potential. Predators prefer certain prey (Sundell et al., 2003), however, the many species of prey in nature affects their ability to attack their preferred prey (Dicke et al., 1989). Testing their food preference by presenting two species of prey in equal numbers separately or together is not enough, as mixtures of different proportions of species of prey could influence a predator's choice of food (Murdoch, 1969; Chesson, 1984). Predators show different behavioural responses, such as (i) preference for a particular species (ii) no preference or null switching, (iii) preference for the most abundant prey, i.e. switching behaviour, and (iv) preference for the less abundant prey, i.e. anti-switching behaviour. Seemingly, prey preference is dependent on multiple factors, viz. prey availability, prey specificity, prey capture time, prey handling time, nutritive value, palatability, promoting fitness, lesser costs of predation, etc. (Hodek \& Evans, 2012).
Most previous studies on prey preferences of predaceous ladybirds (Coleoptera: Coccinellidae) use single species of prey separately and record their effect on consumption and fitness (Omkar \& Bind, 1998; Omkar et al., 1999; Omkar \& Pervez, 2001; Pervez \& Omkar, 2004; Omkar \& Mishra, 2005). However, a preference test is more appropriate when there are several sources of food in the same microhabitat, i.e. a cafeteria setup (Ferrer et al., 2008; Nedved \& Salvucci, 2008; Šenkeříková \& Nedvěd, 2013). In this situation, both adult males and females of the Harlequin ladybird, Harmonia axyridis (Pallas) exhibit different types of response to three different relative abundances of prey, as males prefer certain prey and females do not (Soares et al., 2004). Hodek \& Evans (2012) elucidated the concepts of ladybirds" accepted food in terms of "essential food" (supports both oviposition and development) and "alternative food" (only ensures survival). Essential food provides necessary nutrients needed for egg production and oviposition (Evans \& Gunther, 2005), and hence we consider it as nutritious. Alternative food perhaps lacks these essential

\footnotetext{
* Corresponding author; e-mail: ahmadpervez@yahoo.com
} 
nutrients and/or contains allelochemicals that make it toxic to ladybirds (Hodek \& Evans, 2012). Generalist predators consume alternative prey in order to avoid starving when essential food is scarce (Sherratt et al., 2004). However, certain predators may readily attack alternative prey even when nutritious prey are abundant, as the former may be easier to capture (Lang \& Gosdl, 2001; Provost et al., 2006).

It is likely that when providing essential and alternative foods simultaneously, ladybirds will prefer to consume the former, as it is positively associated with development and reproduction (Omkar \& Mishra, 2005). Mixing certain non-insect foods and/or less abundant prey with the preferred abundant prey may enhance the fitness of predaceous insects (Moser et al., 2008; Lundgren et al., 2009). Hence, it would be interesting to know, how ladybirds respond when provided with both toxic and nutritious prey simultaneously. Keeping in view, the earlier concept of food preference and food availability, it is likely that life stages of ladybirds are more likely to prefer nutritious over toxic prey.

Coccinella septempunctata L. is an aphidophagous ladybird with a wide prey range (Evans, 2000; Omkar \& Pervez, 2002, 2004; Hodek \& Michaud, 2008). However, it is seasonally synchronized with the mustard aphid, Lipaphis erysimi (Kalt.) in North India, which is one of its preferred aphids (Omkar et al., 1999; Ali \& Rizvi, 2007). Omkar \& Srivastava (2003) found L. erysimi to be the most nutritious of six species of aphids tested, in terms of the growth, development and reproduction of $C$. septempunctata. In contrast, this ladybird avoids eating the cabbage aphid, Brevicoryne brassicae L. (Bilashini et al., 2007; Khan \& Khan, 2002; Papachristos et al., 2015), as it sequesters glucosinolates from its host plant and uses them as a defence against predators (Pratt, 2008; Kos et al., 2011, 2012). B. brassicae is even labelled as a rejected prey because of its unpalatability due to its waxy surface (Hodek \& Evans, 2012). Hence, it is likely that $C$. septempunctata will prefer L. erysimi over B. brassicae regardless of whether the former prey is less, equal or more abundant in a mixture of prey. We hypothesized that C. septempunctata will prefer L. erysimi in all proportions of aphid combinations. We also aim to study the effect of the presence of nutritious prey on the toxicity of toxic prey for this ladybird. Hence, the present investigation determines the effect of nutritious and toxic prey on the predatory potential and food preference of larvae and adults of $C$. septempunctata.

\section{MATERIALS AND METHODS}

\section{Stock maintenance}

We collected adults of $C$. septempunctata from agricultural fields near the university campus, Jammu, India $\left(33.7782^{\circ} \mathrm{N}\right.$, $76.5762^{\circ} \mathrm{E}$ ) and brought them to the laboratory. Ten pairs of adults were each kept separately in Petri dishes $(2.0 \mathrm{~cm}$ height $\times 9.0 \mathrm{~cm}$ diameter) and allowed to mate. Thereafter, female ladybirds were each isolated in separate Petri dishes and their egg laying recorded under controlled conditions $\left(25 \pm 2^{\circ} \mathrm{C}, 60 \% \mathrm{RH}\right.$, and 16L: 8D photoperiod) in an Environmental Test Chamber (Remi, India) and the eggs were transferred to other Petri dishes (size as above). At egg hatch the neonates were transferred to prey infested potted plants in acrylic cages $(45 \times 45 \times 45 \mathrm{~cm})$. For the stock maintenance of the two species of aphids: L. erysimi and B. brassicae, two plants: mustard (Brassica campestris) and cabbage (Brassica oleracea) were grown in pots in the laboratory, each replicated many times. We simultaneously maintained parthenogenetic cultures of these aphids on mustard and cabbage plants in the laboratory under the above abiotic conditions.

\section{Predatory potential of $\boldsymbol{C}$. septempunctata}

We determined the predatory potential of the larvae and adults of C. septempunctata fed either L. erysimi (Le) or B. brassicae $(B b)$ in order to quantify aphid consumption in a no choice condition (both daily and total prey consumption). For this purpose, we kept newly hatched first instar larva of $C$. septempunctata in a glass beaker $(11.0 \mathrm{~cm}$ in height and $9.0 \mathrm{~cm}$ in diameter) containing a piece of the host plant infested with 50 third instar nymphs of L. erysimi (host plant as cited above). The beaker was covered with muslin cloth fastened with a rubber band and kept in an Environmental Test Chamber (conditions as above). We recorded moulting every $8 \mathrm{~h}$. After $24 \mathrm{~h}$, the beaker was removed from the chamber and the number of live aphids counted in order to quantify the number of aphids consumed. If moulting had not occurred, the aphids were replenished (same number of aphids as provided the previous day) and this was repeated daily until moulting occurred. At this moult prey consumption was recorded (as above). Thereafter, we provided 100, 200 and 200 third instar nymphs of $L$. erysimi daily to second, third and fourth instar larvae, respectively, until they moulted/pupated and the number of prey consumed by each of these instars was recorded. Similarly, we provided 300 aphids daily to newly emerged adult males and females until they died and recorded the number of prey consumed daily $(\mathrm{n}=10)$. These experiments were repeated using $B$. brassicae as prey.

We tested the data on prey consumption for normality using the Kolmogorov-Smirnoff test and homogeneity of variance using Bartlett's test in statistical software, SAS Ver. 9.0. The data on prey consumption by different stages of $C$. septempunctata were subjected to the two sample t-tests of means in SAS 9.0. The data were also subjected to Two-way ANOVA in SAS 9 with "species" (two levels) and "stage" (six levels) as independent variables and the daily and total prey consumption as dependent variables.

\section{Food preference of $C$. septempunctata}

We offered aphids, $L e$ and $B b$ in three ratios, to first (i.e. $L e: B b$ $12: 38,25: 25$ and 38:12), second (i.e. $L e: B b 25: 75,50: 50,75: 25$ ), third (i.e. $L e: B b 50: 150,100: 100,150: 50$ ) and fourth (i.e. $L e: B b$ $50: 150,100: 100,150: 50$ ) instar larvae, adult males (i.e. $L e: B b$ $75: 225,150: 150$ and 225:75) and females (i.e. Le:Bb 75:225, 150:150 and 225:75) of C. septempunctata and recorded the numbers of each species of aphid consumed after $24 \mathrm{~h}$, using each life stage only once. We calculated Manly's preference index (Manly, 1972) for each treatment using the formula, $\beta=\log \left(\mathrm{N}_{\mathrm{A}} / \mathrm{r}_{\mathrm{A}}\right) /[\log$ $\left.\left(\mathrm{N}_{\mathrm{A}} / \mathrm{r}_{\mathrm{A}}\right)+\log \left(\mathrm{N}_{\mathrm{B}} / \mathrm{r}_{\mathrm{B}}\right)\right]$, in which $\mathrm{N}_{\mathrm{A}}$ and $\mathrm{N}_{\mathrm{B}}$ are the numbers of prey $A$ and prey $B$ offered to a predator and $r_{A}$ and $r_{B}$ are the numbers of unconsumed prey. This index overcomes the problem of an error resulting from prey depletion, i.e. it is applicable in those experiments in which killed prey are not replaced (Cook, 1978; Sherratt \& Harvey, 1993). If $\beta$ is close to 1 , the predator prefers prey $A$ and if close to 0 , prey $B$ is preferred. An index value close to 0.5 indicates no preference. We tested $\beta$ for significant difference from a value of (0.5) using a one sample t-test of the results of each treatment in statistical software, MINITAB 13.0. Prey preference was also analyzed using the $\mathrm{C}$ index, i.e. $\mathrm{C}=\left(\mathrm{E}_{\mathrm{A}}\right.$ $\left.\times \mathrm{N}_{\mathrm{B}}\right) /\left(\mathrm{E}_{\mathrm{B}} \times \mathrm{N}_{\mathrm{A}}\right)\left(\right.$ Sherratt \& Harvey, 1993), where $\mathrm{E}_{\mathrm{A}}$ and $\mathrm{E}_{\mathrm{B}}$ are 
the number of prey A and prey $\mathrm{B}$ consumed. $\mathrm{C}$ value between 0 and 1 indicates a preference for prey $\mathrm{B}$ and a value of more than 1 indicates a preference for prey A. We determined whether the $\mathrm{C}$-index recorded in each treatment was significantly different from one using a one sample t-test in MINITAB 13.0. The Cvalue analysis confirmed the food preference of the predator. We subjected the data on number of prey consumed to Wilcoxon's matched-pairs signed rank test, and the proportion of each prey consumed to two sample t-tests in SAS Version 9.0.

\section{RESULTS}

\section{(i) Predatory potential of C. septempunctata fed either L. erysimi or B. brassicae}

The second $(\mathrm{t}$-value $=6.259 ; \mathrm{P}<0.05$, d.f. $=9)$, third $(\mathrm{t}-$ value $=10.549 ; \mathrm{P}<0.05$, d.f. $=9)$ and fourth instar larvae $(\mathrm{t}$-value $=24.195 ; \mathrm{P}<0.001$, d.f. $=9)$ and adult females (t-value $=7.462 ; \mathrm{P}<0.05$, d.f. $=9)$ of $C$. septempunctata consumed daily a significantly greater number of $L$. erysi$m i$ than $B$. brassicae (Fig. 1). However, the daily consumption of two aphids by first instar larvae $(\mathrm{t}$-value $=1.99 ; \mathrm{P}=$ 0.076 , d.f. $=9)$ and adult males (t-value $=0.514 ; \mathrm{P}=0.621$, d.f. $=9)$ did not differ significantly. Aphid consumption increased with predator stage and age.

The first instar larvae of $C$. septempunctata consumed a significantly greater total number of $L$. erysimi $(27.4 \pm$ $0.88)$ than $B$. brassicae $(22.4 \pm 0.99)(\mathrm{t}$-value $=5.392 ; \mathrm{P}$ $<0.05$, d.f. $=9)$. Similarly, second (t-value $=11.842 ; \mathrm{P}<$ 0.01 , d.f. $=9)$, third (t-value $=19.884 ; \mathrm{P}<0.01$, d.f. $=9$ ) and fourth instar larvae (t-value $=36.70 ; \mathrm{P}<0.001$, d.f. $=$ 9), and adult males ( $\mathrm{t}$-value $=5.856 ; \mathrm{P}<0.05$, d.f. $=9$ ), and females ( $\mathrm{t}$-value $=14.171 ; \mathrm{P}<0.01$, d.f. $=9$ ) each consumed significantly more $L$. erysimi, i.e. $79.9 \pm 1.77,195.8$ $\pm 4.17,307.3 \pm 5.69,1172.8 \pm 14.99$ and $1515.3 \pm 20.56$, respectively, than $B$. brassicae, i.e. $66.8 \pm 2.03,160.3 \pm$ $3.64,209.8 \pm 4.88,1131.9 \pm 17.51$ and $1377.9 \pm 22.18$. The two-way ANOVA revealed that the effects of "species" (F $=86.93 ; \mathrm{P}<0.0001 ;$ d.f. $=1)$ and "stage" $(\mathrm{F}=986.80 ; \mathrm{P}<$ 0.0001 ; d.f. $=5$ ) on daily prey consumption were significant. The interaction between "species" and "stage" was also significant $(\mathrm{F}=12.94 ; \mathrm{P}<0.0001 ;$ d.f. $=5)$. Similarly, the effects of "species" $(\mathrm{F}=70.38 ; \mathrm{P}<0.0001$; d.f. $=1)$ and "stage" $(\mathrm{F}=5879.33 ; \mathrm{P}<0.0001 ;$ d.f. $=5)$ along with the interaction $(\mathrm{F}=10.45 ; \mathrm{P}<0.0001$; d.f. $=5)$ on total prey consumption were also significant.

\section{(ii) Food preference of $C$. septempunctata when provided with mixtures of $L$. erysimi and $B$. brassicae}

The first instar larvae of $C$. septempunctata significantly preferred the more common aphid, L. erysimi, when provided with the $38: 12$ mixture $\left(Z_{(1,18)}=-2.803 ; P=0.005\right.$; Wilcoxon's matched-pairs signed rank test) and $B$. brassicae when provided with the $12: 38$ mixture $\left(Z_{(1,18)}=\right.$ $-1.610 ; \mathrm{P}=0.107)$ and $25: 25$ mixture $\left(\mathrm{Z}_{(1,18)}=-1.659 ; \mathrm{P}=\right.$ 0.09 ). However, second instar larvae preferred L. erysimi when provided with the 75:25 mixture $\left(Z_{(1,18)}=-2.803 ; \mathrm{P}\right.$ $=0.005)$ and $B$. brassicae when provided with the $25: 75$ mixture $\left(Z_{(1,18)}=-2.896 ; P=0.005\right)$. Second instar larvae showed no preference when provided with the two aphids

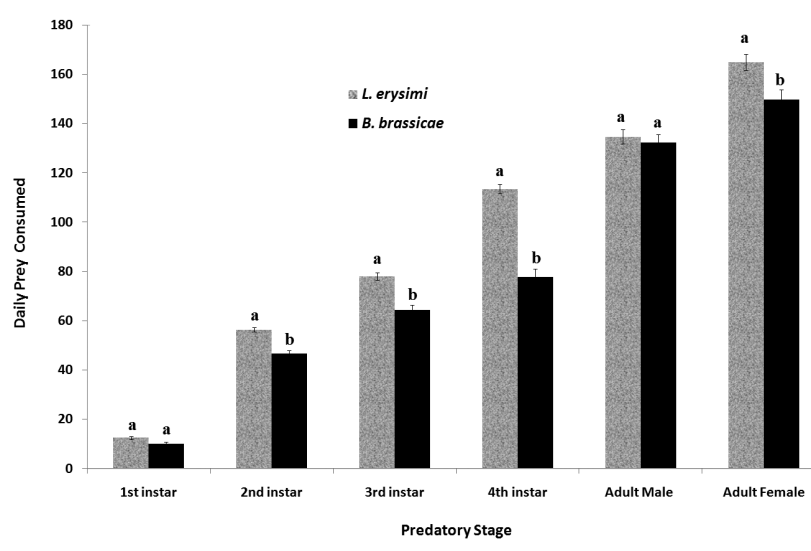

Fig. 1. Daily consumption of two species of aphids by the different stages of $C$. septempunctata in no choice experiments. Error bars denote standard error. Different letters indicate that the data is significant.

in equal numbers (50:50 ratio: $\left.Z_{(1,18)}=-1.659 ; \mathrm{P}=0.139\right)$. The third instar larvae behaved similarly in preferring $L$. erysimi when provided with a $150: 50$ mixture $\left(Z_{(1,18)}=\right.$ $-2.955 ; \mathrm{P}=0.005)$ and $B$. brassicae when provided with a $50: 150$ mixture $\left(Z_{(1,18)}=-2.803 ; \mathrm{P}=0.005\right)$ and no preference when both prey were equally provided (100:100 mixture: $\left.Z_{(1,18)}=-1.689 ; P=0.092\right)$. Fourth instar larvae also preferred L. erysimi when provided with a 150: 50 mixture $\left(\mathrm{Z}_{(1,18)}=-3.658 ; \mathrm{P}=0.002\right)$ and $B$. brassicae when provided with a $50: 150$ mixture $\left(Z_{(1,18)}=-2.788 ; P=0.005\right)$. It also preferred L. erysimi when provided with a $100: 100$ mixture $\left(Z_{(1,18)}=-2.599 ; \mathrm{P}=0.0093\right)$. Adult males also preferred $L$. erysimi when provided with a $225: 75$ mixture $\left(\mathrm{Z}_{(1,18)}=-3.112 ; \mathrm{P}=0.002\right)$ and $B$. brassicae when provided with a $75: 225$ mixture $\left(Z_{(1,18)}=-4.245 ; \mathrm{P}=0.001\right)$ but preferred $L$. erysimi when provided with an equal number of each species (150:150 mixture: $Z_{(1,18)}=-3.345$; $\mathrm{P}=0.002)$. Similarly, adult females preferred L. erysimi when provided with a 225:75 mixture $\left(Z_{(1,18)}=-3.780 ; \mathrm{P}\right.$ $=0.002)$ and $B$. brassicae when provided with a $75: 225$ mixture $\left(Z_{(1,18)}=-2.803 ; P=0.005\right)$ and $L$. erysimi when provided with a an equal number of each species (150:150 mixture: $\left.Z_{(1,18)}=-3.679 ; P=0.002\right)$.

Both the male and female adults consumed a significantly greater proportion of $L$. erysimi than $B$. brassicae in all the mixtures (Fig. 2). This resulted in significantly higher $\beta$ and $\mathrm{C}$ indices and greater positive t-values confirming a preference for L. erysimi (Table 1). The fourth instar larvae significantly preferred $B$. brassicae when provided with the 50:150 (Le:Bb) mixture, and L. erysimi when provided with the other two mixtures. The third instar larvae preferred L. erysimi only when provided with the 150:50 $(L e: B b)$ mixture and showed no preference when provided with the other two mixtures. Second instar larvae preferred $B$. brassicae when provided with the $75: 25$ (Le:Bb) mixture, and both their $\beta$ and $C$ indices had significant negative t-values (Table 1). First instar larvae significantly preferred L. erysimi when provided with the 12:38 (Le:Bb) mixture and $B$. brassicae when provided with the $38: 12$ (Le:Bb) mixture (Fig. 1; Table 1). 

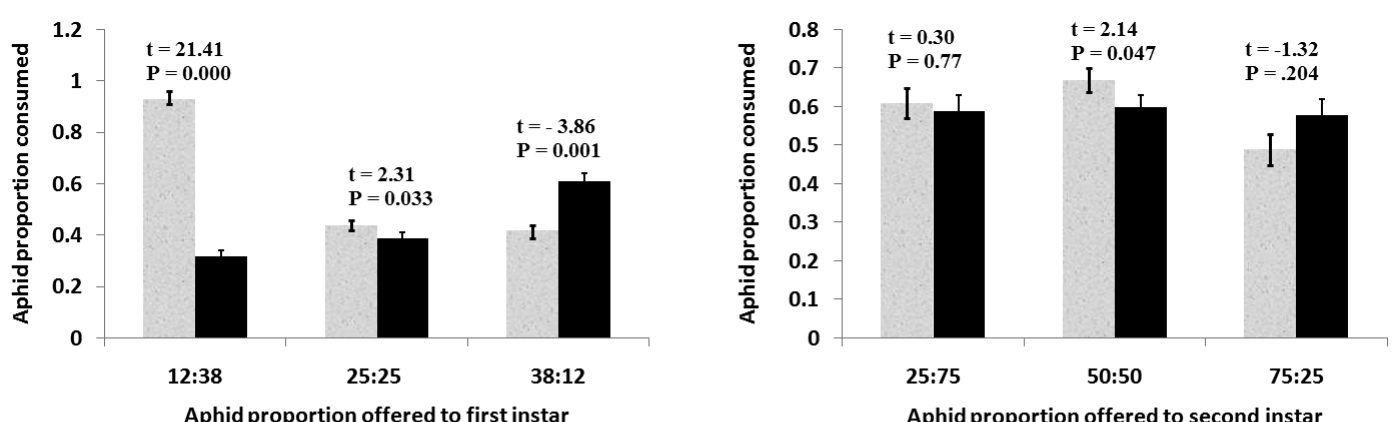

Aphid proportion offered to first instar

Aphid proportion offered to second instar
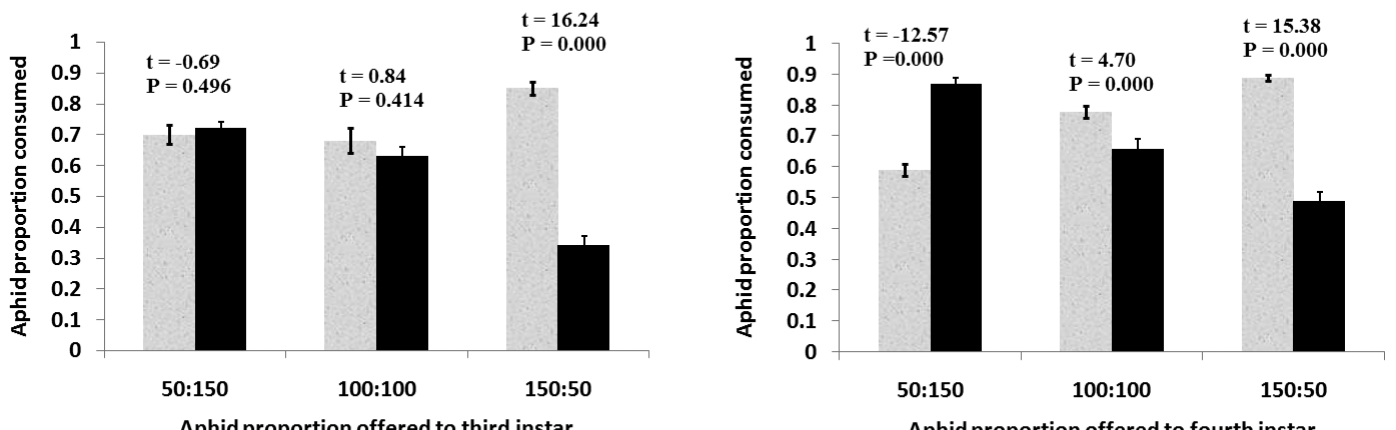

Aphid proportion offered to third instar
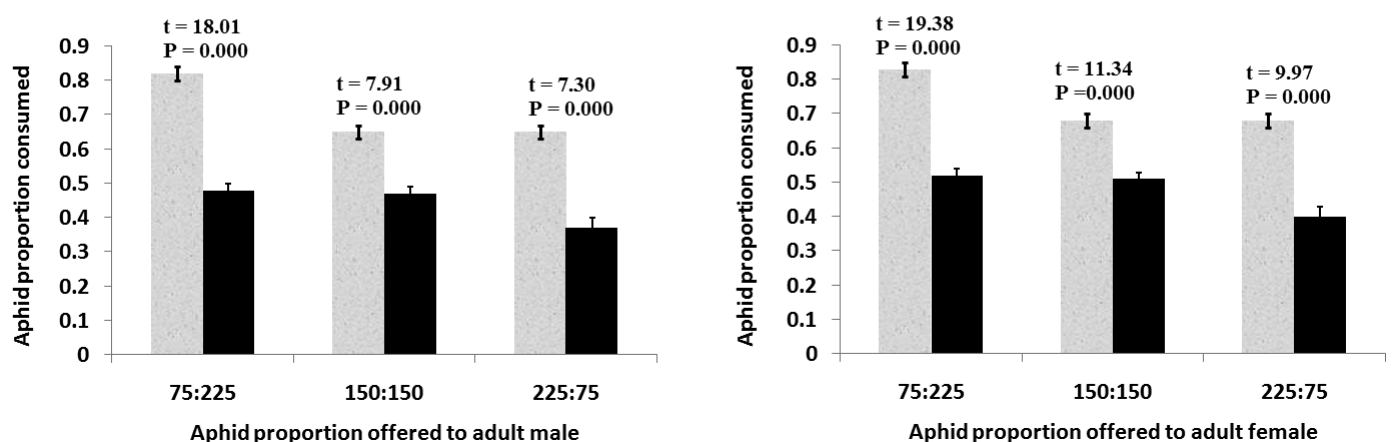

Fig. 2. Proportions of two species of aphids, L. erysimi (grey columns) and B. brassicae (black columns), consumed in choice experiments by the different stages of $C$. septempunctata. The bars at the tops of the columns are standard errors.

Table 1. Mean values of $\beta$ and $C$ recorded for $C$. septempunctata provided with different mixtures of the aphids $L$. erysimi and $B$. brassicae. This predator prefers $L$. erysimi if $\beta$ is close to 1 and $B$. brassicae if $\beta$ is close to 0 , and exhibits no preference if $\beta$ is close to 0.5 . $C$ index more than 1 indicates a preference for $L$. erysimi and between 0 and 1 a preference for $B$. brassicae.

\begin{tabular}{cccccc}
\hline Life stage & Prey ratio & $\beta$ index & $\mathrm{t}$-value & $\mathrm{C}$ index & $\mathrm{t}$-value \\
\hline \multirow{3}{*}{ 1st instar } & $12: 38$ & $0.854 \pm 0.011$ & $\mathrm{t}=33.65 ; \mathrm{P}<0.0001$ & $2.824 \pm 0.108$ & $\mathrm{t}=16.89 ; \mathrm{P}<0.0001$ \\
& $25: 25$ & $0.540 \pm 0.021$ & $\mathrm{t}=1.83 ; \mathrm{P}=0.10$ & $1.152 \pm 0.082$ & $\mathrm{t}=1.85 ; \mathrm{P}=0.10$ \\
& $38: 12$ & $0.3955 \pm 0.039$ & $\mathrm{t}=-2.71 ; \mathrm{P}=0.024$ & $0.728 \pm 0.067$ & $\mathrm{t}=-4.04 ; \mathrm{P}=0.003$ \\
\hline \multirow{3}{*}{ 2nd instar } & $25: 75$ & $0.510 \pm 0.071$ & $\mathrm{t}=0.14 ; \mathrm{P}=0.895$ & $1.367 \pm 0.365$ & $\mathrm{t}=1.00 ; \mathrm{P}=0.341$ \\
& $50: 50$ & $0.547 \pm 0.079$ & $\mathrm{t}=1.89 ; \mathrm{P}=0.10$ & $1.140 \pm 0.070$ & $\mathrm{t}=1.98 ; \mathrm{P}=0.079$ \\
& $75: 25$ & $0.430 \pm 0.028$ & $\mathrm{t}=-2.55 ; \mathrm{P}=0.031$ & $0.854 \pm 0.058$ & $\mathrm{t}=-2.51 ; \mathrm{P}=0.033$ \\
\hline \multirow{3}{*}{ 3rd instar } & $50: 150$ & $0.485 \pm 0.027$ & $\mathrm{t}=-0.54 ; \mathrm{P}=0.604$ & $0.982 \pm 0.053$ & $\mathrm{t}=-0.34 ; \mathrm{P}=0.738$ \\
& $100: 100$ & $0.532 \pm 0.042$ & $\mathrm{t}=0.77 ; \mathrm{P}=0.463$ & $1.093 \pm 0.092$ & $\mathrm{t}=1.01 ; \mathrm{P}=0.337$ \\
& $150: 50$ & $0.822 \pm 0.022$ & $\mathrm{t}=14.51 ; \mathrm{P}<0.0001$ & $2.704 \pm 0.225$ & $\mathrm{t}=7.58 ; \mathrm{P}<0.0001$ \\
\hline \multirow{4}{*}{ 4th instar } & $50: 150$ & $0.307 \pm 0.018$ & $\mathrm{t}=-10.38 ; \mathrm{P}<0.0001$ & $0.683 \pm 0.028$ & $\mathrm{t}=-11.09 ; \mathrm{P}<0.0001$ \\
& $100: 100$ & $0.580 \pm 0.023$ & $\mathrm{t}=3.74 ; \mathrm{P}=0.005$ & $1.211 \pm 0.061$ & $\mathrm{t}=3.42 ; \mathrm{P}=0.005$ \\
& $150: 50$ & $0.763 \pm 0.016$ & $\mathrm{t}=16.08 ; \mathrm{P}<0.0001$ & $1.847 \pm 0.308$ & $\mathrm{t}=8.70 ; \mathrm{P}<0.0001$ \\
\hline \multirow{4}{*}{ Adult Male } & $100: 200$ & $0.721 \pm 0.012$ & $\mathrm{t}=18.56 ; \mathrm{P}<0.0001$ & $1.697 \pm 0.044$ & $\mathrm{t}=15.84 ; \mathrm{P}<0.0001$ \\
& $150: 150$ & $0.623 \pm 0.020$ & $\mathrm{t}=6.25 ; \mathrm{P}<0.0001$ & $1.402 \pm 0.074$ & $\mathrm{t}=5.43 ; \mathrm{P}<0.0001$ \\
& $200: 100$ & $0.700 \pm 0.033$ & $\mathrm{t}=5.97 ; \mathrm{P}<0.0001$ & $2.022 \pm 0.248$ & $\mathrm{t}=4.12 ; \mathrm{P}<0.0001$ \\
\hline \multirow{3}{*}{ Adult Female } & $100: 200$ & $0.708 \pm 0.012$ & $\mathrm{t}=17.72 ; \mathrm{P}<0.0001$ & $1.599 \pm 0.040$ & $\mathrm{t}=14.67 ; \mathrm{P}<0.0001$ \\
& $150: 150$ & $0.618 \pm 0.13$ & $\mathrm{t}=9.35 ; \mathrm{P}<0.0001$ & $1.355 \pm 0.046$ & $\mathrm{t}=7.78 ; \mathrm{P}<0.0001$ \\
& $200: 100$ & $0.687 \pm 0.023$ & $\mathrm{t}=8.33 ; \mathrm{P}<0.0001$ & $1.765 \pm 0.132$ & $\mathrm{t}=5.80 ; \mathrm{P}<0.0001$ \\
\hline
\end{tabular}




\section{DISCUSSION}

In no choice experiments most life stages of $C$. septempunctata consumed a greater number of $L$. erysimi than $B$. brassicae. This is largely ascribed to the high protein content of $L$. erysimi along with its seasonal synchrony with C. septempunctata (Atwal \& Sethi, 1963; Omkar \& Srivastava, 2003). In north India, three species of aphids: L. erysimi, Myzus persicae (Sulzer) and B. brassicae, infest Brassica crops in succession from December to March (Bilashini et al., 2007). Infestations of L. erysimi in the fields and the arrival there of C. septempunctata are synchronized (Sharma et al., 1997). Dense infestations of $L$. erysimi give rise to an abundance of $C$. septempunctata, and the decline of L. erysimi in February is associated with the appearance of the first colonies of $B$. brassicae, which is a poorer quality prey (Bilashini et al., 2007; Bilashani \& Singh, 2009). Coccinella septempunctata is strongly correlated with L. erysimi in terms of its abundance and weakly so with B. brassicae (Bilashini et al., 2007). Reduced consumption of $B$. brassicae recorded in our study could explain the low numbers of $C$. septempunctata in this crop at this time (Ahuja et al., 2010).

The significant main effects of "species" on daily and total prey consumption recorded in the no choice experiment indicate that larvae and adults $C$. septempunctata responded differently to the two aphids provided and prefer L. erysimi. Similarly, the significant main effect of "stage" on prey consumption reveals that different larval stages and adults have different quantitative dietary requirements. Prey consumption progressively increased with age and is associated with the increased food requirements for sustaining their growth and metabolism as they increased in size. In addition, the trend with increase in size was independent of the species of aphid provided. However, owing to the toxic nature of $B$. brassicae, it was expected that fewer of this species would be consumed. The first instar probably needs a certain biomass of prey in order to complete its development and as its sensory ability is probably poorly developed compared to that of following instars it consumes the same numbers of both species of aphid. Female ladybirds are more voracious than male ladybirds, as more prey are needed to maintain their bigger body size and develop their gonads (Rhamhalinghan, 1987; Lucas et al., 1997).

The lower consumption of $B$. brassicae by most of the stages of $C$. septempunctata is largely ascribed to glucosinolates, which the aphid sequesters from its host plant and uses as a defense against predaceous ladybirds (Pratt, 2008; Kos et al., 2011, 2012). In addition, endogenous myrosinase in $B$. brassicae cumulatively forms hydrolytic products with glucosinolates that could be even more toxic for aphid predators (Francis et al., 2002; Kos et al., 2011, 2012). Furthermore, powdery wax on the surface of the body of $B$. brassicae possibly makes it less attractive and palatable for $C$. septempunctata.

The choice experiment revealed that overall the larvae, and adult males and females of $C$. septempunctata prefer L. erysimi. This partially supports our hypothesis that $C$. septempunctata will prefer L. erysimi when provided with different mixtures of the two aphids. Mostly, the larvae show no preference when provided with equal numbers of each species of aphid and in a few instances, they consume a greater proportion of B. brassicae than L. erysimi.

Nedved \& Salvucci (2008) found that C. septempunctata consumes the toxic aphid, Aphis sambuci L. at twice the rate of two essential aphid species: Acyrthosiphon pisum (Harris) and Aphis philadelphi. Similarly, adult male, $H$. axyridis consume more of the toxic aphid, A. sambuci than of the suitable prey Aphis fabae cirsiiacanthoidis (syn. A. philadelphi) (Šenkeř́ková \& Nedvěd, 2013). First instar larvae of Adalia bipunctata (L.) attack and consume more of the toxic aphid, Aphis craccivora Koch than the nutritious aphid, A. pisum, whilst fourth instar larvae exhibited a null switching response by choosing none (Ferrer et al., 2008). We also recorded for larvae, that the toxic and rejected prey, B. brassicae (Hodek \& Evans, 2012) was readily consumed and even preferred on a few occasions. Hence, providing mixtures of nutritious and toxic aphids might overcome any nutritive deficiency and/or decrease the toxicity of a toxic diet for larvae. Our results also support the finding of Soares et al. (2004), in which adult females of $H$. axyridis showed a null switching response to a mixed aphid diet. The inferred dietary self-selection behaviour of $H$. axyridis probably accounts for a mixed prey diet being more suitable than a single prey diet for this predator (Soares et al., 2004). Thus, it is likely that when L. erysimi is scarce the need for protein in the diet (Atwal \& Sethi, 1963) is met by consuming B. brassicae, especially when it is abundant. Rana et al. (2002) comment that ladybirds may prefer toxic prey over essential prey if continuously reared on the former for a few generations. Such findings create doubts about the preference of ladybirds for the most nutritious prey and threaten the validity of the established definitions of preferred, essential, alternative and toxic foods (Hodek \& Honek, 1996; Hodek \& Evans, 2012). We conclude that $B$. brassicae is not toxic for or rejected by $C$. septempunctata and a mixed diet of $B$. brassicae and L. erysimi could be beneficial for the development of this ladybird. In addition the different life stages of $C$. septempunctata (i) quantitatively consume more $L$. erysimi than $B$. brassicae when provided with each of these aphids separately, and (ii) adults prefer L. erysimi regardless of the proportion of this species in a mixed diet, (iii) larvae did not show a prey preference on most occasions and readily attacked both of the aphids provided.

ACKNOWLEDGEMENTS. AP is thankful to the Science and Engineering Research Board, Department of Science and Technology, Government of India for financial assistance (EMR/2016/006296).

\section{REFERENCES}

Ahuja I., Rohloff J. \& Bones A.M. 2010: Defence mechanisms of Brassicaceae: implications for plant-insect interactions and potential for integrated pest management: A review. - Agron. Sustain. Devel. 30: 311-348. 
Ali A. \& Rizvi P.Q. 2007: Development and predatory performance of Coccinella septempunctata L. (Coleoptera: Coccinellidae) on different prey species. - J. Biol. Sci. 7: 1478-1483.

Atwal A.S. \& Sethi S.L. 1963: Biochemical basis for food preference of a predator beetle. - Curr. Sci. 32: 511-512.

BILAShinI Y. \& Singh T.K. 2009: Studies on population dynamics and feeding potential of Coccinella septempunctata Linnaeus in relation to Lipaphis erysimi (Kaltenbach) on cabbage. Ind. J. Appl. Entomol. 23: 99-103.

BILASHINI Y., SingH T.K. \& SingH R.K.R. 2007: Biological control potential of Coccinella septempunctata Linnaeus (Coleoptera: Coccinellidae) on major homopteran pests of rapeseed. $-J$. Biol. Contr. 21: 157-162.

Chesson P.L. 1984: Variable predators and switching behavior. Theor. Popul. Biol. 26: 1-26.

Cook M.J.W. 1978: The assessment of preference. - J. Anim. Ecol. 47: 805-816.

Dicke M., Sabelis M.W. \& van den Berg H. 1989: Does prey preference change as a result of prey species being presented together? Analysis of prey selection by the predatory mite $T y$ phlodromus pyri (Acarina: Phytoseiidae). - Oecologia 81 302-309.

Evans E.W. 2000: Morphology of invasion: body size patterns associated with establishment of Coccinella septempunctata (Coleoptera: Coccinellidae) in western North America. - Eur. J. Entomol. 97: 469-474.

Evans E.W. \& GunTher D.I. 2005: The link between food and reproduction in aphidophagous predators: a case study with Harmonia axyridis (Coleoptera: Coccinellidae). - Eur. J. Entomol. 102: 423-430.

Ferrer A., Dixon A.F.G. \& Hemptinne J.-L. 2008: Prey preference of ladybird larvae and its impact on larval mortality, some life-history traits of adults and female fitness. - Bull. Insectol. 61: 5-10.

Francis F., Lognay G., Wathelet J.P. \& Haubruge E. 2002: Characterisation of aphid myrosinase and degradation studies of glucosinolates. - Arch. Insect Biochem. Physiol. 50: 173-182.

Hodek I. \& Evans E.W. 2012: Food relationship. In Hodek I., van Emden H.F. \& Honek A. (eds): Ecology and Behaviour of Ladybird Beetles (Coccinellidae). Wiley-Blackwell, Chichester, pp. 141-274.

Hodek I. \& HoneK A. 1996: Ecology of Coccinellidae. Kluwer Academic Publishers, Dordrecht, Boston, London, 464 pp.

Hodek I. \& Michaud J.P. 2008: Why is Coccinella septempunctata so successful? (A point-of-view). - Eur. J. Entomol. 105: $1-12$.

Khan M.R. \& Khan M.R. 2002: Prey preference and switching behaviour of Coccinella septempunctata L. (Coleoptera: Coccinellidae). - Int. J. Agric. Biol. 4: 110-112.

Kos M., Kabouw P., Noordam R., Hendriks K., Vet L.E.M., Van Loon J.J.A. \& Dicke M. 2011: Prey-mediated effects of glucosinolates on aphid predators. - Ecol. Entomol. 36: 377-388.

Kos M., Houshyani B., Achhami B.B., Wietsma R., Gols R., Weldegergis B.T., Kabouw P., Bouwmeester H.J., Vet L.E.M., Dicke M. \& LOON J.J.A. 2012: Herbivore-mediated effects of glucosinolates on different natural enemies of a specialist aphid. - J. Chem. Ecol. 38: 100-115.

LANG A. \& GsodL S. 2001: Prey vulnerability and active predator choice as determinants of prey selection: a carabid beetle and its aphid prey. - J. Appl. Entomol. 125: 53-61.

Lucas E., Coderre D. \& Vincent C. 1997: Voracity and feeding preferences of two aphidophagous coccinellids on Aphis citricola and Tetranychus utricae. - Entomol. Exp. Appl. 85: 151-159.
Lundgren J.G., Hesler L.S., Tilmon K.J., Dashiell K.E. \& ScotT R. 2009: Direct effects of soybean varietal selection and Aphis glycines-resistant soybeans on natural enemies. - Arthr.-Plant Interact. 3: 9-16.

MANLY B.F.J. 1974: Tables for the analysis of selective predation experiments. - Res. Popul. Ecol. 14: 74-81.

Moser S.E., Harwood J.D. \& OBrycKi J.J. 2008: Larval feeding on Bt hybrid and non-Bt corn seedlings by Harmonia axyridis (Coleoptera: Coccinellidae) and Coleomegilla maculata (Coleoptera: Coccinellidae). — Environ. Entomol. 37: 525-533.

Murdoch W.W. 1969: Switching in general predators: experiments on predator specificity and stability of prey populations. - Ecol. Monogr. 39: 335-354.

Nedved O. \& Salvucci S. 2008: Ladybird Coccinella septempunctata (Coleoptera: Coccinellidae) prefers toxic prey in laboratory choice experiment. - Eur. J. Entomol. 105: 431-436.

OMKAR \& Bind R.B. 1998: Prey preference of a ladybird beetle, Cheilomenes (= Menochilus) sexmaculata (Fabr.). $-J$. Aphidol. 12: 63-66.

OMKAR \& Mishra G. 2005: Preference-performance of a generalist predatory ladybird: A laboratory study. - Biol. Contr. 34: 187-195.

Omkar \& Pervez A. 2001: Prey preference of a ladybeetle, Micraspis discolor (Fabricius). - Entomon 26: 195-197.

OmKar \& Pervez A. 2002: Ecology of aphidophagous ladybird beetle, Coccinella septempunctata Linn. (Coleoptera: Coccinellidae): A review. - J. Aphidol. 16: 175-201.

OMKar \& Pervez A. 2004: Predaceous coccinellids in India: Predator-prey catalogue. — Orient. Insects 38: 27-61.

Omkar, James B.E. \& SRivastava S. 1999: Prey preference of a ladybeetle, Coccinella transversalis Fabricius (Coleoptera: Coccinellidae). - Adv. Biosci. 18: 117-122.

OMKAR \& SRIVASTAVA S. 2003: Influence of six aphid prey species on development and reproduction of a ladybird beetle, Coccinella septempunctata. - BioControl 48: 379-393.

Papachristos D.P., Katsarou I., Michaelakis A. \& Papanikolaou N.E. 2015: Influence of different species of aphid prey on the immature survival and development of four species of aphidophagous coccinellids (Coleoptera: Coccinellidae). - Eur. J. Entomol. 112: 440-445.

Pervez A. \& OmKar 2004: Prey dependent life attributes of an aphidophagous ladybird beetle, Propylea dissecta (Mulsant). — Biocontr. Sci. Technol. 14: 385-396.

Provost C., Lucas E., Coderre D. \& Chouinard G. 2006: Prey selection by the ladybeetle Harmonia axyridis: The influence of prey mobility and prey species. - J. Insect Behav. 19: 265277.

PRATT C. 2008: Accumulation of glucosinolates by the cabbage aphid Brevicoryne brassicae as a defense against two coccinellid species. - J. Chem. Ecol. 34: 323-329.

Rana J.S., Dixon A.F.G. \& Jaroší V. 2002: Costs and benefits of prey specialization in a generalist insect predator. - J. Anim. Ecol. 71: 15-22.

RHAMHALIGHAN M. 1987: Seasonal variation in ovular output in Coccinella septempunctata L. (Coleoptera: Coccinellidae). In Palanicchami S. (ed.): Proc. 5th Indian Symposium Invert. Reprod. Dept. Zool., Arulmigu Palani Andavar, College of Arts and Culture, Palani, India, pp. 149-157.

ŠENKEŘíKOVÁ P. \& NeDVĚD O. 2013: Preference among three aphid species by predatory ladybird beetle Harmonia axyridis in laboratory. - IOBC-WPRS Bull. 94: 123-130.

Sharma D.K., VanNa G.C. \& Arora B.S. 1997: Population build up and interrelationship of Lipaphis erysimi (Kalt.) with its natural enemies on some Brassica crops. - J. Aphidol. 11: $161-166$. 
Sherratt T.N. \& Harvey I.F. 1993: Frequency - dependent food selection by arthropods a review. — Biol. J. Linn. Soc. 48: 167-186.

Sherratt T.N., Speed M.P. \& Ruxton G.D. 2004: Natural selection on unpalatable species imposed by state-dependent foraging behaviour. - J. Theor. Biol. 228: 217-226.

Soares A.O., Coderre D. \& Schanderl H. 2004: Dietary selfselection behavior by the adults of the aphidophagous ladybee- tle Harmonia axyridis (Coleoptera: Coccinellidae). — J. Anim. Ecol. 73: 478-486.

Sundell L., Eccard J.A., Tillikainen R. \& Ylonen H. 2003: Predation rate, prey preference and predator switching: experiments on voles and weasels. - Oikos 101: 615-623.

Received February 1, 2017; revised and accepted September 14, 2017 Published online October 9, 2017 